\title{
Implementation of a targeted screening program to detect airflow obstruction suggestive of chronic obstructive pulmonary disease within a presurgical screening clinic
}

\author{
Chantal Robitaille PhD ${ }^{1}$, Esther Dajczman RN MScA ${ }^{1,2,3}$, Andrew M Hirsch MD ${ }^{1}$, David Small MD ${ }^{1}$, \\ Pierre Ernst MD MSc${ }^{1}$, Dana Porubska BScN², Mark Palayew MD ${ }^{1}$
}

\begin{abstract}
C Robitaille, E Dajczman, AM Hirsch, et al. Implementation of a targeted screening program to detect airflow obstruction suggestive of chronic obstructive pulmonary disease within a presurgical screening clinic. Can Respir J 2015;22(4):209-214.
\end{abstract}

BACKGROUND: Targeted spirometry screening for chronic obstructive pulmonary disease (COPD) has been studied in primary care and community settings. Limitations regarding availability and quality of testing remain. A targeted spirometry screening program was implemented within a presurgical screening (PSS) clinic to detect undiagnosed airways disease and identify patients with COPD/asthma in need of treatment optimization.

OBJECTIVE: The present quality assurance study evaluated airflow obstruction detection rates and examined characteristics of patients identified through the targeted screening program.

METHODS: The targeted spirometry screening program was implemented within the PSS clinic of a tertiary care university hospital. Current or ex-smokers with respiratory symptoms and patients with a history of COPD or asthma underwent prebronchodilator spirometry. History of airways disease and smoking status were obtained during the PSS assessment and confirmed through chart reviews.

RESULTS: After exclusions, the study sample included 449 current or ex-smokers. Abnormal spirometry results were found in $184(41 \%)$ patients: $73(16 \%)$ had mild, 93 (21\%) had moderate and $18(4 \%)$ had severe or very severe airflow obstruction. One hundred eighteen (26\%) new cases of airflow obstruction suggestive of COPD were detected. One-half of these new cases had moderate or severe airflow obstruction. Only 34\% of patients with abnormal spirometry results had reported a previous diagnosis of COPD. More than one-half of patients with abnormal spirometry results were current smokers.

CONCLUSIONS: Undiagnosed airflow obstruction was detected in a significant number of smokers and ex-smokers through a targeted screening program within a PSS clinic. These patients can be referred for early intervention and secondary preventive strategies.

Key Words: Airflow obstruction; Chronic obstructive pulmonary disease; Screening; Spirometry
La mise en œuvre d'un programme de dépistage ciblé pour déceler une obstruction des voies respiratoires évocatrice d'une maladie pulmonaire obstructive chronique dans une clinique de dépistage préchirurgical

HISTORIQUE : Le dépistage ciblé de la maladie pulmonaire obstructive chronique (MPOC) par spirométrie a fait l'objet d'études en première ligne et en milieu communautaire. Des limites subsistent quant à la disponibilité et à la qualité des tests. Un programme ciblé de dépistage par spirométrie a été mis en œuvre dans une clinique de dépistage préchirurgical (DPC) pour déceler les maladies des voies respiratoires non diagnostiquées et dépister les patients atteints de MPOC ou d'asthme dont le traitement doit être optimisé.

OBJECTIF : La présente étude de contrôle de la qualité visait à évaluer le taux de détection des obstructions des voies respiratoires et à examiner les caractéristiques des patients dépistés grâce au programme de dépistage ciblé.

MÉTHODOLOGIE : Le programme de dépistage ciblé par spirométrie a été mis en œuvre au sein de la clinique de DPC d'un hôpital universitaire de soins tertiaires. Les fumeurs ou anciens fumeurs ayant des symptômes respiratoires et les patients ayant des antécédents de MPOC ou d'asthme ont subi une spirométrie avant la bronchodilatation. L'évaluation à la clinique de DPC a permis d'obtenir les antécédents de maladie des voies respiratoires et de vérifier le tabagisme, qui ont été confirmés lors de l'analyse des dossiers.

RÉSULTATS : Après les exclusions, l'échantillon à l'étude se composait de 449 fumeurs ou anciens fumeurs. Ainsi, 184 patients (41\%) ont obtenu des résultats de spirométrie anormaux : 73 (16\%) présentaient une obstruction des voies respiratoires légère, 93 (21\%) une obstruction modérée et 18 (4\%) une obstruction grave ou très grave. Les chercheurs ont décelé 118 nouveaux cas (26\%) d'obstruction des voies respiratoires évocateurs d'une MPOC, dont la moitié avait une obstruction modérée ou grave. Seuls $34 \%$ des patients ayant des résultats de spirométrie anormaux ont déclaré un diagnostic antérieur de MPOC. Plus de la moitié des patients ayant des résultats de spirométrie anormaux étaient fumeurs.

CONCLUSIONS : Un nombre important de fumeurs et d'anciens fumeurs présentait une obstruction non diagnostiquée des voies respiratoires décelée grâce à un programme de dépistage ciblé dans une clinique de DPC. Ces patients peuvent être dirigés vers une intervention précoce et des stratégies préventives secondaires.
Chronic obstructive pulmonary disease (COPD) is highly prevalent, affecting $9 \%$ to $26 \%$ of individuals $\geq 40$ years of age, and is the fourth leading cause of death in Canada (1-4). More than 750,000 Canadian adults report being diagnosed with COPD by a health care professional (5). COPD appears to be underdiagnosed because prevalence rates based on spirometry testing are two to six times higher than estimates based on patients' self-reports of a physician diagnosis $(6,7)$.

Early diagnosis and management of COPD is important because it is a leading cause of hospitalization and emergency department visits (8-12). Early detection enables the initiation of treatment, if needed, and for secondary preventive strategies including smoking cessation, education and healthy lifestyle changes (13-15). The Canadian Thoracic Society recommends spirometry testing for individuals at risk for COPD: individuals $>40$ years of age with a past or present smoking history and at least one respiratory symptom, such as breathlessness, wheezing, cough, or persistent phlegm and frequent lung infections (16). Despite the simplicity of spirometry, limitations regarding access, use, quality and interpretation of results are considerable $(17-19)$.

A novel targeted screening program was implemented within the presurgical screening (PSS) clinic of a tertiary care hospital. This was initiated in response to indications that avoidable postoperative pulmonary complications were occurring in patients with previously undiagnosed COPD and in COPD patients with poorly controlled disease. A quality assurance study was performed to evaluate the detection rate of airflow obstruction and to examine the characteristics of individuals identified through the targeted screening program.

\footnotetext{
${ }^{1}$ Airways Centre, Division of Pulmonary Diseases; ${ }^{2}$ Department of Nursing, Jewish General Hospital, McGill University; ${ }^{3}$ Mount Sinai Hospital, Montreal, Quebec

Correspondence: Dr Mark Palayew, Airways Centre, Division of Pulmonary Diseases, Jewish General Hospital, 3755 Cote Ste Catherine,

Pavilion G, Room 203, Montreal, Quebec H3T 1E2. Telephone 514-340-7900, e-mail mpalayew@pne.jgh.mcgill.ca
} 


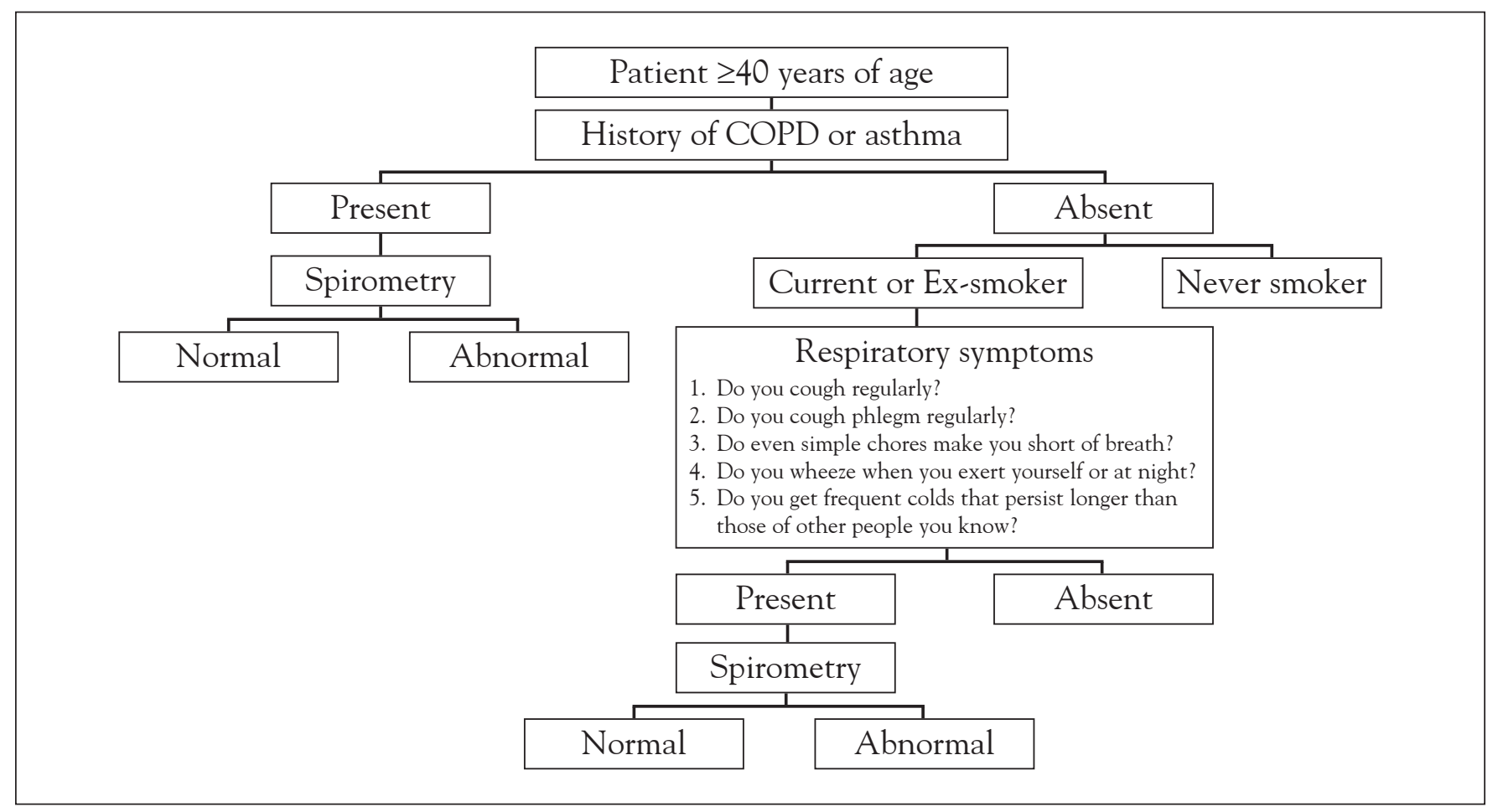

Figure 1) Presurgical screening clinic algorithm for targeted airflow obstruction spirometry screening. COPD Chronic obstructive pulmonary disease

\section{METHODS}

\section{Description of the program}

A walk-in spirometry service for patients referred for testing is offered as part of a dedicated Airways Centre within the Respirology Division of the Jewish General Hospital (JGH, Montreal, Quebec). This is open to the hospital community at large and used extensively by respirologists for patient evaluation, follow-up and education. In June 2010, a targeted COPD screening program was developed and implemented in collaboration with the hospital's PSS clinic. The PSS clinic sees all hospital patients undergoing interventional procedures and elective surgery except those scheduled for coronary artery bypass grafts. Patients meeting the criteria of the targeted COPD screening algorithm were referred for spirometry: current or ex-smokers (packyears $>10$ ), $\geq 40$ years of age and reporting at least one respiratory symptom on the Canadian Lung Health Test (20). During the history and physical examination, patients were asked about history of COPD and asthma. Patients reporting a history of COPD or asthma were also sent for presurgical spirometry regardless of pulmonary symptoms or smoking status (Figure 1).

Prebronchodilator spirometry was performed by a registered respiratory therapist according to American Thoracic Society standards (21) using a Spiro USB spirometer (Cardinal Health, Spirometry PC Software, version 1.5.0.0). Calibration of the device was performed daily. Measurements were taken with the patient in a seated position with a nose clip. Forced expiratory manoeuvres were repeated until three acceptable and reproducible measurements were obtained. The best forced expiratory volume in $1 \mathrm{~s}\left(\mathrm{FEV}_{1}\right)$ and forced vital capacity (FVC) were recorded, and $\mathrm{FEV}_{1} / \mathrm{FVC}$ was calculated. Predicted values for $\mathrm{FEV}_{1}$ were calculated using the equations reported by Knudson et al (22). Height and weight were measured wearing indoor clothing without shoes. A written interpretation based on American Thoracic Society criteria was automatically generated. The spirometry results were reviewed by a respirologist. Based on the results and respirologist interpretation, the PSS clinic decided whether to request a respirology consultation where further evaluation and testing was performed before surgery. The present study was approved by the JGH Research Ethics Committee (Ethics \# CR12-37).

\section{Participants and setting}

Patients referred for spirometry from the PSS clinic of the JGH between July 2010 and August 2012 were included in the present study. Patients who were never smokers (pack-years $\leq 10$ ) were excluded from the sample. Only the first screening spirometry was included for patients referred more than once during the study period. Patients presenting for a preoperative screening spirometry outside of the algorithm (eg, directly from surgeons) were excluded from the analyses. Patients with unacceptable spirometry quality or for whom essential information was missing (eg, medical history, smoking history) were also excluded.

\section{Procedures}

Spirometry results were classified based on modified Global Initiative for Chronic Obstructive Lung Disease (GOLD) criteria (23). Because postbronchodilator spirometry results were not available, prebronchodilator results were used to estimate severity. The hospital in- and outpatient record was reviewed to confirm the presence or absence of airways disease history provided during the PSS clinic assessment. Smoking status, pack-year history and presurgical respirology consultations were also reviewed. Pack-years were defined as the number of cigarettes smoked per day divided by 20 and multiplied by the number of years that the patient smoked. Patients with abnormal spirometry results were classified according to whether this was a new or a known diagnosis. Patients were categorized as new cases if they denied having a history of COPD during their preadmission evaluation and no previous diagnosis of COPD was found in their hospital record. Those whose hospital record indicated a diagnosis of COPD, including questionable diagnoses such as COPD/asthma, were categorized as having known COPD. Demographic and physiological parameters were compiled. Frequencies, means and SDs were calculated. $\chi^{2}$ statistical analyses were conducted. All analyses were performed using SPSS version 19 (IBM Corporation, USA). Statistical significance was defined as $\mathrm{P}<0.05$.

\section{RESULTS}

Between July 2010 and August 2012, 694 patients were referred for spirometry; after exclusions, 449 were included for analysis (Figure 2). Age ranged from 41 to 90 years. Two hundred thirty-four (52\%) patients 


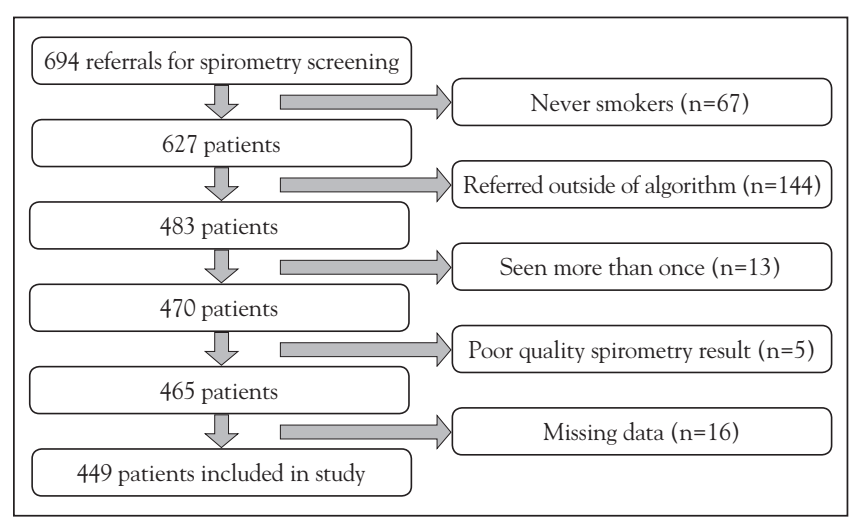

Figure 2) Diagram of study participant selection process

\section{TABLE 1}

\section{Patient demographics $(n=449)$}

\begin{tabular}{lr}
\hline Age, years, mean \pm SD & $65.3 \pm 10.9$ \\
Sex & $260(58)$ \\
Male & $189(42)$ \\
Female & \\
Smoking status & $234(52)$ \\
Current smoker & $215(48)$ \\
Ex-smoker & $37 \pm 22$ \\
Pack-years, mean \pm SD & \\
History of chronic obstructive pulmonary disease & $87(19)$ \\
Present & $362(81)$ \\
Absent & \\
\hline
\end{tabular}

Data presented as $n$ (\%) unless otherwise indicated

were smokers and 215 (48\%) were ex-smokers (Table 1). Only 3\% of patients referred for targeted spirometry screening were scheduled for thoracic surgery. Twenty-seven percent of patients were scheduled for abdominal surgery, and $67 \%$ for other general surgical procedures. Information regarding the type of surgery was missing for $3 \%$ of patients due to cancellation. According to modified GOLD criteria, 184 (41\%) patients had abnormal spirometry: 73 (16\%) had mild, 93 (21\%) had moderate and $18(4 \%)$ had severe or very severe airflow obstruction (Figure 3). Following a review of hospital records, it was determined that the abnormal spirometry results observed in six patients were due to asthma rather than airflow obstruction suggestive of COPD. One hundred eighteen patients were new-found cases of airflow obstruction suggestive of COPD while 60 were already known for having COPD, representing $26 \%$ and $13 \%$ of the screened population, respectively. Only $34 \%$ of patients with abnormal spirometry had a history of COPD. Of the known COPD cases, 49 (82\%) had at least moderate airflow obstruction. One-half (50\%) of patients with newly identified airflow obstruction had moderate to severe airflow obstruction (Figure 4). Patients with known COPD were significantly more likely to have more advanced modified GOLD stage COPD than patients who were newly identified $\left(\chi^{2}=17.7 ; \mathrm{P}<0.001\right)$.

More than one-half $(51 \%)$ of patients with abnormal spirometry results were still smoking at the time of screening. Significantly more patients were still smoking among those newly recognized with airflow obstruction compared with those with previously documented COPD ( $58 \%$ versus $37 \%$, respectively; $\chi^{2}=7.0 ; \mathrm{P}<0.01$ ).

\section{COPD misdiagnosis}

A medical history of COPD was found in the charts of 68 patients. Spirometry and chart reviews including examination of chest $\mathrm{x}$-rays and/or computed tomography scans, when available, revealed that the criteria for COPD diagnosis were not met in nine (13\%) cases. All nine cases showed no evidence of airflow obstruction on screening spirometry and one was believed to have asthma based on history.

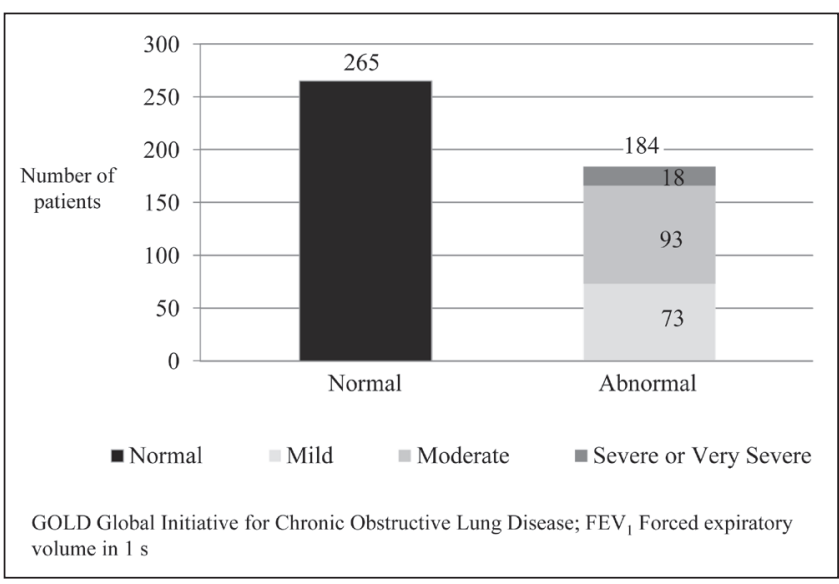

Figure 3) Spirometry results classified accordong to modified GOLD criteria (Mild: $F E V_{1} \geq 80 \%$; Moderate: $50 \% \leq F E V_{1}<80 \%$; Severe: $\left.\mathrm{FEV}_{1}<50 \%\right)$

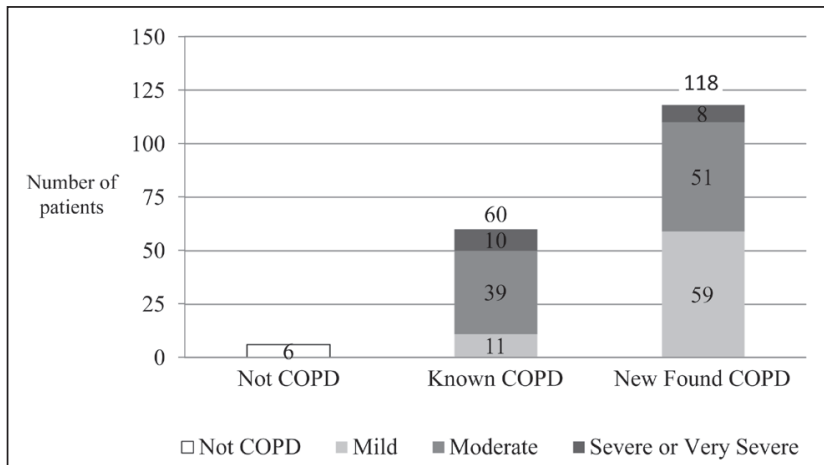

GOLD Global Initiative for Chronic Obstructive Lung Disease; COPD Chronic obstructive pulmonary disease; $\mathrm{FEV}_{1}$ Forced expiratory volume in $1 \mathrm{~s}$

Figure 4) Modified GOLD classification according to known or new-found chronic obstructive pulmonary disease (COPD) (Mild: FEV $1 \geq 80 \%$; Moderate: $50 \% \leq \mathrm{FEV}_{1}<80 \%$; Severe: $\mathrm{FEV}_{1}<50 \%$ )

\section{DISCUSSION}

The results of the present study indicate that a targeted spirometry screening program to detect airflow obstruction suggestive of COPD integrated within a PSS clinic is both feasible and effective. Only a small proportion of patients referred for spirometry were unable to perform the test, while an important number of patients with undiagnosed COPD were identified as having airflow obstruction suggestive of COPD. Forty percent of screened patients were identified as having airflow obstruction. Of those referred for targeted screening, 26\% represented newly detected cases while $13 \%$ were already known to have COPD. Only $34 \%$ of patients with airflow obstruction had a history of COPD. One-half of the patients with newly recognized airflow obstruction had at least moderate airflow obstruction. More than 50\% of the patients with abnormal spirometry were still smoking.

COPD is a prevalent disease and a significant burden to patients and the health care system $(5,11)$. Screening programs using spirometry have been used to estimate the true prevalence of COPD. Multiple population screening studies involving adults $>40$ years of age report prevalence rates of $9 \%$ to $26 \%(1-3,24)$. The utility of population spirometry screening programs for the detection of COPD is controversial (25). Screening of asymptomatic individuals has been criticized, leading to recent guidelines recommending against population screening for $\operatorname{COPD}(26,27)$. There is, however, evidence to suggest that targeted screening strategies may be useful (28-31). The Canadian Thoracic Society guidelines, therefore, recommend targeted screening of patients at risk for COPD (16). COPD screening studies 
of at-risk individuals (current and former smokers, $\geq 40$ years of age, with a smoking history $\geq 10$ pack-years) using spirometry report prevalence rates of $23 \%$ to $30 \%(32,33)$. More recently, the Canadian Cohort of Obstructive Lung Disease (CanCOLD) study, a multisite Canadian study, reported a prevalence rate of GOLD stage $\geq 2$ COPD in a cohort of at-risk patients ( $>40$ years of age, a minimum 20 packyear smoking history, visiting a primary care practitioner) of 21\% (34). The present study found an overall prevalence of airflow obstruction suggestive of COPD of $41 \%$ based on spirometry. The higher rates demonstrated in the present study may be due to the use of prebronchodilator values and to the added requirement that those referred have a positive Canadian Lung Health Test and, therefore, were symptomatic. As in the CanCOLD study, approximately two-thirds of our screened patients with positive spirometry results were not previously aware of their diagnosis (34).

Spirometry has also been used to estimate the prevalence of COPD according to severity of illness. The CanCOLD study reports prevalence rates of $16 \%$ for moderate COPD (GOLD 2) and $4 \%$ for severe COPD (GOLD 3 or 4 ) in high-risk patients (34). We found that $16 \%$, $21 \%$ and $4 \%$ of screened patients had mild, moderate, and severe or very severe airflow obstruction, respectively. One-half of the newly detected patients had mild airflow obstruction, suggesting that these patients were identified early in the disease trajectory. Most importantly, however, $50 \%$ of new-found cases had moderate, severe or very severe airflow obstruction. These individuals may be at higher risk for exacerbations, rapid functional decline and, in this presurgical context, postoperative complications (35).

Patients are often diagnosed with COPD without spirometry testing $(18,36,37)$. Our targeted screening program identified nine patients (13\%) with a history of COPD unsupported by spirometry and clinical criteria. This result is in agreement with the misdiagnosis rate of $13 \%$ identified in a study conducted in the primary care setting (34).

There is evidence that early detection and diagnosis of COPD is beneficial to patients $(38,39)$. A recent review concluded that the most rapid rate of $\mathrm{FEV}_{1}$ decline occurs during GOLD stage 2 disease and suggests that it would be beneficial if COPD could be diagnosed and addressed before this period (40). Early identification enables access to secondary preventive care, of which smoking cessation is the most important (41-43). Smoking cessation in patients with mild COPD has been shown to slow the progression of $\mathrm{FEV}_{1}$ decline (13-15). Providing patients with spirometry evidence helps optimize smoking cessation counselling and efforts (44-47). Eighty-four percent of Canadians $>35$ years of age with self-reported COPD were or had been smokers at the time of diagnosis and almost $40 \%$ continued to smoke (5). In a cohort of patients at risk for COPD, Hill et al (34) reported that almost 50\% were current smokers. Similarly, in the present study, 51\% of patients with abnormal spirometry were current smokers. Of those newly identified with airflow obstruction, $58 \%$ were smokers. There are other potentially beneficial early interventions. Recent guidelines for the prevention of acute exacerbations recommend that patients with COPD receive yearly influenza vaccination (43). Furthermore, there is evidence that the introduction of maintenance pharmacotherapy during the early stages of COPD may be beneficial $(39,40)$.

Our targeted screening program for COPD was implemented within a presurgical screening clinic following our anecdotal experience with postsurgical complications in patients with undiagnosed or suboptimally treated COPD. Patients with COPD have high hospital admission and readmission rates $(10,48)$. They are also at higher risk for postoperative complications such as exacerbations, thus increasing length of stay and cost to the health care system $(35,49,50)$. We saw an opportunity to develop a targeted program allowing for optimization of those with undiagnosed and uncontrolled COPD before surgery.

We opted to include modified GOLD stage 1 (ie, prebronchodilator) patients within our classification criteria. Some authors have questioned whether GOLD stage 1 should be regarded as early COPD (51). For the sake of simplicity, GOLD guidelines defined airway limitation as a postbronchodilator fixed ratio of $\mathrm{FEV}_{1} / \mathrm{FVC}<0.70$ (23).
This does not take into account studies demonstrating an age-related decline in $\mathrm{FEV}_{1} / \mathrm{FVC}$ in healthy individuals resulting in overdiagnosis in older age groups (51-55). To reduce the risk of overdiagnosis, some screening studies have opted to analyze their data according to GOLD stage $\geq 2$ (ie, $\mathrm{FEV}_{1} / \mathrm{FVC}<0.70$ and $\mathrm{FEV}_{1}<80 \%$ predicted value $(1,34)$. Studies have shown, however, that patients potentially 'over diagnosed' with COPD according to GOLD classification are, in fact, at higher risk for having COPD-related hospitalizations and mortality in the long-term $(40,56,57)$. A recent study has shown that patients with mild COPD demonstrate evidence of clinically important physiological impairments (58). Furthermore, a meta-analysis examining exacerbation rates according to GOLD stage indicates that COPD exacerbations also occur in mild COPD (59). It has been argued that one way to reduce hospital admissions is to detect undiagnosed COPD patients so that they may be started on appropriate therapy earlier (11). Considering the important costs associated with this chronic disease and that hospital admissions for acute exacerbations of COPD account for $82 \%$ of the costs incurred $(60,61)$, a targeted spirometry screening program has potential for significant cost savings.

Our targeted spirometry screening intervention did not include postbronchodilator spirometry, which may have resulted in an overestimation of identification rates. However, to be accessible, screening interventions should be inexpensive, quick and simple to administer. The rationale to using postbronchodilator spirometry is primarily to exclude asthma. To limit the potential impact of asthma on our results, never smokers were excluded from the analyses. Furthermore, the presence or absence of bronchodilator reversibility is unlikely to impact the diagnosis of symptomatic moderate to severe COPD because airflow obstruction in such patients is not likely to normalize (6). In our study, $60 \%$ of patients with abnormal spirometry results had moderate to severe airflow obstruction.

This spirometry screening program targeted at-risk patients who scored positive on the Canadian Lung Health Test. Various other casefinding questionnaires have been proposed to aid in optimizing the use of spirometry screening (62-68). A comparison of the sensitivity and specificity of these questionnaires would be useful to maximize the impact of a targeted program integrated within a PSS clinic. It would also be beneficial to evaluate the impact of this targeted screening program on healthy lifestyle changes (smoking cessation, physical activity), disease management, exacerbations and hospitalizations. Further studies are needed to evaluate the impact of the targeted presurgical COPD screening program on peri- and postoperative complications. Of particular interest would be the impact on in-hospital pulmonary complication rates, postoperative length of stay and readmissions rates due to respiratory causes.

\section{CONCLUSION}

Our findings showed that a targeted preoperative screening program for patients at risk for COPD is feasible and effective. Undiagnosed airflow obstruction can be detected in a significant number of smokers and former smokers. One-half of newly identified patients had at least moderate disease. Furthermore, many continued to smoke. This program provides an opportunity to impact disease progression in patients who would otherwise have remained undiagnosed through pharmacotherapy and secondary preventive interventions including smoking cessation.

AUTHOR CONTRIBUTIONS \& ACKNOWLEDGEMENTS: $\mathrm{ED}, \mathrm{AH}, \mathrm{DS}, \mathrm{PE}, \mathrm{DP}$ and MP conceived and developed the program. All authors were involved in the study design. $\mathrm{CR}$ and $\mathrm{ED}$ acquired the data. CR analyzed the data and wrote the manuscript. ED, AH, DS, PE, DP and MP provided critical revisions to the manuscript for intellectual content. All authors gave final approval of the version to be published. The authors thank the respiratory therapists working in the PFT lab as well as the staff of the Presurgical Screening Clinic for their support in this study.

FUNDING: This study was supported by an unrestricted grant from Associated Respiratory Holdings. 


\section{REFERENCES}

1. Buist AS, McBurnie MA, Vollmer WM, et al. International variation in the prevalence of COPD (The BOLD Study): A population-based prevalence study. Lancet 2007;370:741-50.

2. Halbert RJ, Natoli JL, Gano A, Badamgarav E, Buist AS, Mannino DM. Global burden of COPD: Systematic review and meta-analysis. Eur Respir J 2006;28:523-32.

3. Tan WC, Bourbeau J, Fitzgerald JM, et al. Regional variation in the severity of COPD in Canada: The multisite population-based prevalence study (COLD Study). Am J Respir Crit Care Med 2010;181:A4111.

4. Statistics Canada. Leading causes of death in Canada, 2009. <www.statcan.gc.ca/pub/84-215-x/84-215-x2012001-eng.htm> (Accessed October 28, 2013).

5. Public Health Agency of Canada. Life and breath: Respiratory disease in Canada. Ottawa, 2007.

6. Evans J, Chen Y, Camp PG, Bowie DM, McRae L. Estimating the prevalence of COPD in Canada: Reported diagnosis versus measured airflow obstruction. Statistics Canada, Health Reports March 2014;25:3-11.

7. Schirnhofer L, Lamprecht B, Vollmer WM, et al. COPD prevalence in Salzburg, Austria: Results from the burden of obstructive lung disease (BOLD) study. Chest 2007;131:29-36.

8. CDC/NCHS. Hospital discharges by first-and any-listed listed diagnosis: US, 1990-2010 (Source: NHDS).

<http://205.207.175.93/HDI/ReportFolders/reportFolders.aspx> (Accessed September 18, 2014).

9. Canadian Institute of Health Information. A snapshot of health care in Canada as demonstrated by top 10 lists, 2011. 2011. Report Number: ISBN 978-1-77109-037-7.

10. Canadian Institute of Health Information. Inpatient hospitalizations, surgeries and childbirth indicators in 2012-2013. 2014. Report Number: 7757-0614.

11. Benady S. The human and economic burden of COPD: A leading cause of hospital admission in Canada. Ottawa: Canadian Thoracic Society, 2010.

12. Mitchell KE, Johnson-Warrington V, Apps LD, et al. A self-management programme for COPD: A randomised controlled trial. Eur Respir J 2014 2014;44:1538-47.

13. Anthonisen NR. The benefits of smoking cessation. Can Respir J 2003; 10:422-3

14. Anthonisen NR, Connett JE, Kiley JP, et al. Effects of smoking intervention and the use of an inhaled anticholinergic bronchodilator on the rate of decline of $\mathrm{FEV}_{1}$ : The Lung Health Study. JAMA 1994;272:1497-505.

15. Anthonisen NR, Connett JE, Murray RP. Smoking and lung function of lung health study participants after 11 years. Am J Respir Crit Care Med 2002;166:675-9.

16. O'Donnell DE, Aaron S, Bourbeau J, et al. Canadian Thoracic Society recommendations for management of chronic obstructive pulmonary disease - 2007 update. Can Respir J 2007;14(Suppl B):5B-32B.

17. Canadian Lung Association. Chronic obstructive pulmonary disease (COPD): A national report card. <www.lung.ca/_resources/2005. copd_reportcard.pdf $>$ (Accessed July 16, 2014).

18. Yu WC, Fu SN, Tai EL-b, et al. Spirometry is underused in the diagnosis and monitoring of patients with chronic obstructive pulmonary disease (COPD). Int J Chron Pulmon Dis 2013;8389-95.

19. Lamprecht B, Mahringer A, Soriano JB, Kaiser B, Buist AS, Studnicka M. Is spirometry properly used to diagnose COPD? Results from the BOLD study in Salzburg, Austria: A populationbased analytical study. Prim Care Respir J 2013;22:195-200.

20. Canadian Lung Association. Canadian Lung Health Test. $<$ www.lung.ca/diseases-maladies/copd-mpoc/signs-signes/ COPDQuiz-MPOCQuiz_e.php> (Accessed April 30, 2010).

21. Miller MR, Hankinson J, Brusasco V, et al. Standardisation of spirometry. Eur Respir J 2005;26:319-38.

22. Knudson RJ, Lebowitz MD, Holberg CJ, Burrows B. Changes in the normal maximal expiratory flow-volume curve with growth and aging. Am Rev Respir Dis 1983;127:725-34.

23. Global Initiative for Chronic Obstructive Lung Disease (GOLD). Global Strategy for the Diagnosis, Management and Prevention of COPD. <www.goldcopd.org/> (Accessed September 6, 2012).

24. Haroon S, Jordan R, O'Beirne-Eliman J, Adab P. The case finding yield for COPD in primary care: A systematic review and meta-analysis.
B43. COPD: Screening and Diagnostic Tools: American Thoracic Society; 2014:A2956-A2956.

25. Barclay L. Screening for COPD with spirometry reviewed. Medscape Medical News <www.medscape.com/viewarticle/571200> (Accessed October 28, 2013).

26. U.S. Preventive Services Task Force. Screening for chronic obstructive pulmonary disease using spirometry: U.S. preventive services task force recommendation statement. Ann Intern Med 2008;148:529-34.

27. Qaseem A, Wilt TJ, Weinberger SE, et al. Diagnosis and management of stable chronic obstructive pulmonary disease: A clinical practice guideline update from the American College of Physicians, American College of Chest Physicians, American Thoracic Society, and European Respiratory Society. Ann Intern Med 2011;155:179-91.

28. Celli BR, MacNee W, Agusti A, et al. Standards for the diagnosis and treatment of patients with COPD: A summary of the ATS/ERS position paper. Eur Respir J 2004;23:932-46.

29. Enright PL, Crapo RO. Controversies in the use of spirometry for early recognition and diagnosis of chronic obstructive pulmonary disease in cigarette smokers. Clin Chest Med 2000;21:645-52.

30. Mclvor AR, Tashkin DP. Underdiagnosis of chronic obstructive pulmonary disease: A rationale for spirometry as a screening tool. Can Respir J 2001;8:153-8.

31. Eaton T, Withy S, Garrett JE, Mercer J. Spirometry in primary care practice: The importance of quality assurance and the impact of spirometry workshops. Chest 1999;116:416-23.

32. Zielinski J, Bednarek M, Gòrecka D, et al. Increasing COPD awareness. Eur Respir J 2006;27:833-52.

33. Zielinski J, Bednarek M. Early detection of COPD in a high-risk population using spirometric screening. Chest 2001;119:731-6.

34. Hill K, Goldstein RS, Guyatt GH, et al. Prevalence and underdiagnosis of chronic obstructive pulmonary disease among patients at risk in primary care. CMAJ 2010;182:673-8.

35. Smetana GW, Lawrence VA, Cornell JE. Preoperative pulmonary risk stratification for noncardiothoracic surgery: Systematic review for the American College of Physicians. Ann Intern Med 2006;144:581-95.

36. Ghattas C, Dai A, Gemmel DJ, Awad MH. Over diagnosis of chronic obstructive pulmonary disease in an underserved patient population. Int J Chron Pulmon Dis 2013;8:545-9.

37. Bourbeau J, Sebaldt RJ, Day A, et al. Practice patterns in the management of chronic obstructive pulmonary disease in primary practice: The CAGE study. Can Respir J 2008;15:13-9.

38. Guenette J. New insights into the pathophysiology of mild chronic obstructive pulmonary disease. Can Respir J 2014;21:25-7.

39. Price D, Freeman D, Cleland J, Kaplan A, Cerasoli F. Earlier diagnosis and earlier treatment of COPD in primary care. Prim Care Respir J 2011;20:15-22.

40. Csikesz NG, Gartman EJ. New developments in the assessment of COPD: Early diagnosis is key. Int J Chron Pulmon Dis 2014;9:277-86

41. O'Donnell DE, Hernandez P, Kaplan A, et al. Canadian Thoracic Society recommendations for management of chronic obstructive pulmonary disease - 2008 update - highlights for pirmary care. Can Respir J 2008;15(Suppl A):1A-8A.

42. Viegi G, Pistelli F, Sherrill DL, Maio S, Baldacci S, Carrozzi L. Definition, epidemiology and natural history of COPD. Eur Respir J 2007;30:993-1013.

43. Criner GJ, Bourbeau J, Diekemper RL, et al. Prevention of acute exacerbations of chronic obstructive pulmonary disease: American College of Chest Physicians and Canadian Thoracic Society guideline. Chest October 16, 2014 (Epub ahead of print).

44. Stratelis G, Mölstad S, Jakobsson P, Zetterström O. The impact of repeated spirometry and smoking cessation advice on smokers with mild COPD. Scand J Prim Health Care 2006;24:133-9.

45. Parkes G, Greenhalgh T, Griffin M, Dent R. Effect on smoking quit rate of telling patients their lung age: The Step2quit randomised controlled trial. BMJ 2008;336:598-600.

46. Bednarek M, Gòrecka D, Wielgomas J, et al. Smokers with airway obstruction are more likely to quit smoking. Thorax 2006;61:869-73.

47. Risser N, Belcher D. Adding spirometry, carbon monoxide, and pulmonary symptom results to smoking cessation counseling. J Gen Intern Med 1990;5:16-22. 
48. Canadian Institute of Health Information. Health indicators 2008. Ottawa: CIHI;2008. Report Number: ISBN: 978-1-77109-037-7.

49. Chang JK, Calligaro KD, Lombardi JP, Dougherty MJ. Factors that predict prolonged length of stay after aortic surgery. J Vasc Surg 2003;38:335-9.

50. Dimick JB, Chen SL, Taheri PA, Henderson WG, Khuri SF, Campbell Jr DA. Hospital costs associated with surgical complications: A report from the private-sector National Surgical Quality Improvement Program. J Am Coll Surg 2004;199:531-7.

51. Hardie JA, Buist AS, Vollmer WM, Ellingsen I, Bakke PS, Morkve O. Risk of over-diagnosis of COPD in asymptomatic elderly neversmokers. Eur Respir J 2002;20:1117-22.

52. Hnizdo E, Glindmeyer HW, Petsonk EL, Enright P, Buist AS. Case definitions for chronic obstructive pulmonary disease. COPD 2006;3:95-100.

53. Stanojevic S, Wade A, Stocks J, et al. Reference ranges for spirometry across all ages: A new approach. Am J Respir Crit Care Med 2008;177:253-60.

54. Pellegrino R, Viegi G, Brusasco V, et al. Interpretative strategies for lung function tests. Eur Respir J 2005;26:948-68.

55. Hansen JE, Sun XG, Wasserman K. Spirometric criteria for airway obstruction: Use percentage of $\mathrm{FEV}_{1} / \mathrm{FVC}$ ratio below the fifth percentile, not $<70 \%$. Chest 2007;131:349-55.

56. Mannino DM, Buist AS, Vollmer WM. Chronic obstructive pulmonary disease in the older adult: What defines abnormal lung function? Thorax 2007;62:237-41.

57. Mannino DM, Diaz-Guzman E. Interpreting lung function data using $80 \%$ predicted and fixed thresholds identifies patients at increased risk of mortality. Chest 2012;141:73-80.

58. Guenette JA, Chin RC, Cheng S, et al. Mechanisms of exercise intolerance in Global Initiative for Chronic Obstructive Lung Disease grade 1 COPD. Eur Respir J 2014;44:1177-87.
59. Hoogendoorn M, Feenstra TL, Hoogenveen RT, Al M, Mölken MR. Association between lung function and exacerbation frequency in patients with COPD. Int J Chron Obstruct Pulmon Dis 2010;5:435-44

60. Maleki-Yazdi MR, Kelly SM, Lam SS, Marin M, Barbeau M, Walker V. The burden of illness in patients with moderate to severe chronic obstructive pulmonary disease in Canada. Can Respir J 2012;19:319-24

61. Mittmann N, Kuramoto L, Seung SJ, Haddon JM, Bradley-Kennedy C, FitzGerald JM. The cost of moderate and severe COPD exacerbations to the Canadian healthcare system. Respir Med 2008;102:413-21.

62. Hill K, Hodder R, Blouin M, Heels-Ansdell D, Guyatt G, Goldstein R. Identifying adults at risk of COPD who need confirmatory spirometry in primary care. Can Fam Physician 2011;57:e51-e57.

63. Price DB, Tinkelman DG, Halbert RJ, et al. Symptom-based questionnaire for identifying COPD in smokers. Respiration 2006;73:285-95.

64. van Schayck CP. Detecting patients at a high risk of developing chronic obstructive pulmonary disease in general practice: Cross sectional case finding study. BMJ 2002;324:1370.

65. Leidy NK, Murray L, Steenrod A, et al. Can we find undiagnosed, high-risk patients with COPD in primary care? Qualitative results of a multi-method study to develop a new screening tool. Am J Respir Crit Care Med 2014;189:A2960.

66. Lyngso A, Backer V, Gottlieb V, Nybo B, Ostergaard M, Frolich A. Early detection of COPD in primary care - The Copenhagen COPD Screening Project. BMC Public Health 2010;10:524.

67. Martinez FJ, Raczek AE, Seifer FD, et al. Development and initial validation of a self-scored COPD Population Screener questionnaire (COPD-PS). COPD 2008;5:85-95.

68. Franco-Marina F, Fernandez-Plata R, Torre-Bouscoulet L, et al. Efficient screening for COPD using three steps: A cross-sectional study in Mexico City. NPJ Prim Care Respir Med 2014;24. 


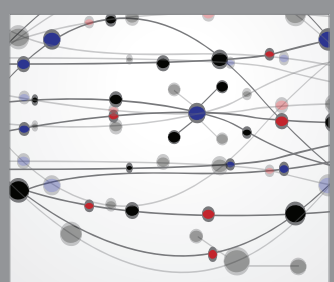

The Scientific World Journal
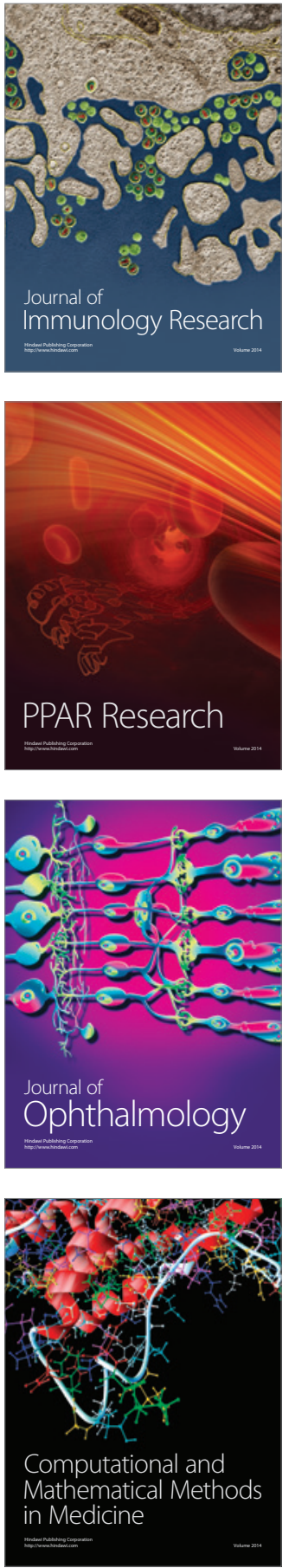

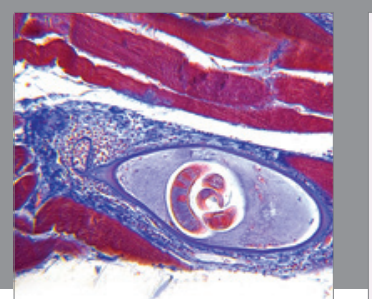

Gastroenterology Research and Practice

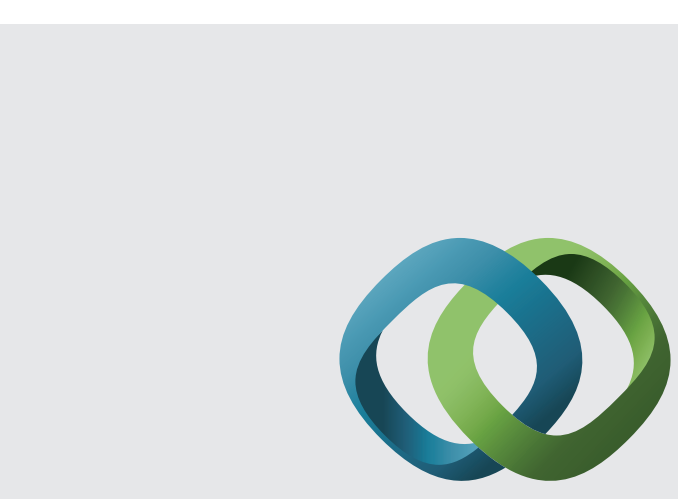

\section{Hindawi}

Submit your manuscripts at

http://www.hindawi.com
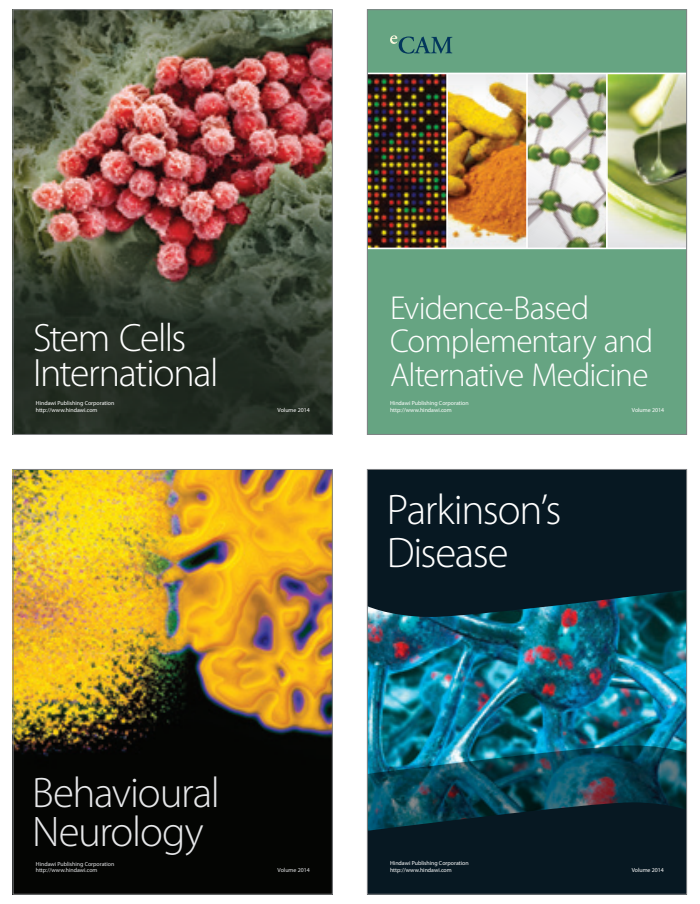
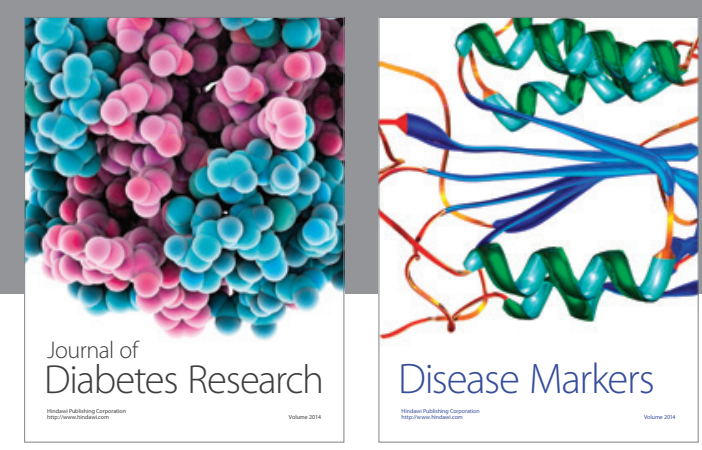

Disease Markers
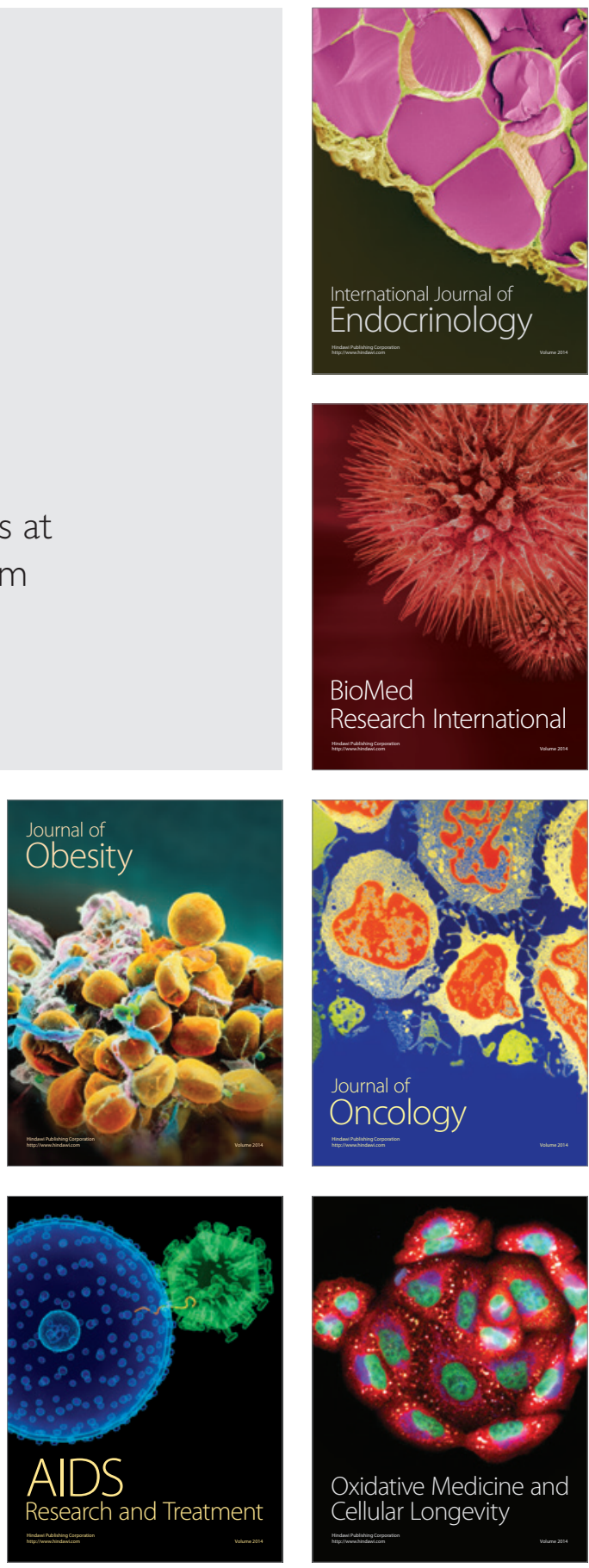